\title{
Regulation of Hepatic Triglyceride Synthesis in Diabetic Rats
}

\author{
Veeraraghavan K. MURThy and JosePh C. Shipp, Departments of Internal \\ Medicine and Biochemistry, University of Nebraska College of Medicine; \\ Omaha Veterans Administration Medical Center, Omaha, Nebraska 68105
}

A B S T RACT The syntheses of triglyceride and its precursors were increased when liver homogenates of ketotic diabetic rats were incubated with $\left[\mathrm{U}-{ }^{14} \mathrm{C}\right]-$ glycero 3-phosphate and cofactors. Triolein sonicates produced a concentration-dependent inhibition of the synthesis of both diglyceride and triglyceride, whereas monoolein sonicates had no effect. Rat serum very low density lipoproteins, like triolein sonicates, inhibited the synthesis of diglyceride and triglyceride. Furthermore, the intracellular form of very low density lipoproteins, namely nascent very low density lipoproteins, also inhibited the synthesis of diglyceride and triglyceride. A higher apparent $I_{50}$ (concentration of inhibitor that produces $50 \%$ inhibition of activity) was observed in liver homogenates of ketotic diabetic rats for inhibition of triglyceride or diglyceride synthesis by triolein sonicates, serum very low density lipoproteins, high density lipoproteins, and nascent very low density lipoproteins. Insulin treatment of the diabetic rats reversed the $I_{50}$ values to control.

In studies on the site of inhibition of triglyceride synthesis in the overall biosynthetic pathway, serum very low density lipoproteins produced a concentrationdependent inhibition of liver cytosolic phosphatidate phosphohydrolase activity. A higher $I_{50}$ value was obtained with the hepatic enzyme of the diabetic rats. This higher $I_{50}$ value was reversed to control by insulin treatment of the diabetic rats. These results indicated that the activity of this enzyme was less sensitive to inhibition by very low density lipoproteins in the ketotic diabetic state. The reduced sensitivity of phosphatidate phosphohydrolase activity to triglyceride inhibition observed in the present studies could explain our previous observation of an increased rate of triglyceride synthesis in ketotic diabetic liver homogenates.

This work was presented in part at the American Diabetes Association Annual Meeting at Los Angeles, Calif., 1979. Diabetes. 28: 357.

Address reprint requests to Dr. Murthy.

Received for publication 30 July 1979 and in revised form 5 December 1980.

\section{INTRODUCTION}

Previous studies in our laboratory characterized the severity of the diabetic state required for an accumulation of hepatic triglycerides $(\mathrm{TG})^{1}$ in rats rendered diabetic with various amounts of streptozotocin (1). A consistent 10-50-fold increase in hepatic TG content was observed in ketotic diabetic rats (1). Further studies in liver homogenates of ketotic diabetic rats demonstrated an increased substrate flux through the TG biosynthetic pathway and increases in the activity of the key enzymes of TG synthesis (1). An increased hepatic TG synthesis in livers of ketotic diabetic rats at a time when there was accumulation of TG suggested that the regulation of TG synthesis in these livers might have been impaired. Factors that regulate TG synthesis in liver have not been established. It is known that the synthesis of a variety of metabolites in the cell is regulated through feedback inhibition. These facts prompted us to study the potential control of hepatic TG synthesis by end product, namely, TG.

The purpose of this investigation was $(a)$ to study the possible inhibition of TG synthesis in liver homogenates of control and diabetic rats by added triolein sonicates or a physiological form of TG, i.e., very low density lipoproteins (VLDL), (b) if an inhibition was observed, to establish the site of inhibition of TG synthesis in the TG synthetic pathway, and $(c)$ to study the effect of insulin treatment of the ketotic diabetic rats on the kinetics of inhibition of TG synthesis.

\section{METHODS}

The sources of rats, chemicals, insulin, and methods for the induction of ketotic diabetes, insulin treatment of the diabetic rats, and assay for TG synthesis from $\left[\mathrm{U}^{11} \mathrm{C}\right]$ glycero3 -phosphate in liver homogenates were as described $(1,2)$. Triolein and 1-monoolein were obtained from Serdary Research Laboratories, London, Canada.

Preparation of triolein or monoolein sonicates. The lipid

\footnotetext{
'Abbreviations used in this paper: DG, 1:2 diglyceride, HDL, high density lipoproteins; PA, phosphatidate; TG, triglycerides; V'LDL, very low density lipoproteins.
} 
was dissolved in a minimal volume of chloroform; $50 \mathrm{mM}$

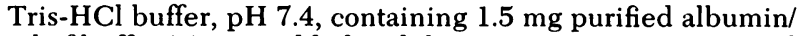
$\mathrm{ml}$ of buffer (1), was added and the suspension was sonicated at $2^{\circ} \mathrm{C}$ for $30 \mathrm{~s}$ (Biosonik IV, Bronwill Instruments, Rochester, N. Y.). $\mathrm{N}_{2}$ gas was passed through the suspension at $37^{\circ} \mathrm{C}$ until it was free of chloroform. The sonicates were used within 30 min of preparation.

Preparation of serum VLDL. 36-h fasted male rats (280-320 g body wt) were decapitated and their blood was collected. The serum was separated and EDTA, pH 7.4, (1 $\mathrm{mg} / \mathrm{ml}$ of serum) was added. The serum was centrifuged (model $\mathrm{L}_{3} 50$ ultracentrifuge, Beckman Instruments, Spinco Div., Fullerton, Calif.) at $100,000 \mathrm{~g}$ for $1 \mathrm{~h}$ and any chylomicrons present were removed by tube slicing. The density of the infranatant fluid was adjusted to 1.006 with $\mathrm{KBr}$ and VLDL was isolated by ultracentrifugation as described by Havel et al. (3). The VLDL preparation was floated through saline $(1.006 d)$ and dialyzed under $\mathrm{N}_{2}$ pressure at $4^{\circ} \mathrm{C}$ as described by Murthy et al. (4). Further concentration was achieved by centrifuging on Centriflo membranes (Amicon Corp., Lexington, Mass.).

Preparation of doubly labeled serum VLDL. 36-h fasted male rats $(280-320 \mathrm{~g})$ were each injected intravenously with $0.2 \mathrm{ml}$ of rat serum containing $1 \mu \mathrm{mol}$ potassium palmitate-1${ }^{14} \mathrm{C}(20 \mu \mathrm{Ci})$ and $0.005 \mu \mathrm{mol}\left[2{ }^{3} \mathrm{H}\right]$ glycerol $(30 \mu \mathrm{Ci})$. After 30 min, the rats were decapitated, serum was collected, and VLDL was isolated, washed, and concentrated as described above. The radioactive VLDL contained $\sim 0.5 \times 10^{6} \mathrm{dpm}{ }^{14} \mathrm{C}$ and $0.4 \times 10^{6} \mathrm{dpm}{ }^{3} \mathrm{H} / \mu \mathrm{mol}$ of VLDL-TG.

Preparation of nascent VLDL. Rat liver nascent VLDL was prepared as described by Mahley et al. $(5,6)$ except that purified bovine serum albumin $(1 \mathrm{mg} / \mathrm{ml})$ was present during the sonication of the suspension of the golgi apparatus. The inclusion of albumin greatly reduced the aggregation of the released nascent VLDL.

Preparation of rat serum high density lipoprotein (HDL). Rat serum HDL ( $\mathrm{HDL}_{2}+\mathrm{HDL}_{3}$ ) was isolated at density 1.075 $<d<1.21$ (7). HDL was washed with saline $d 1.21$, dialyzed and concentrated as described for serum VLDL. The VLDL preparations exhibited a single band with pre-beta mobility and HDL a single band with alpha mobility on agarose gel electrophoresis (8). Data obtained in incubation studies were analyzed (9) and plotted by a Hewlett-Packard Computer (model 9821 A, Hewlett-Packard Co., Palo Alto, Calif.) equipped with a plotter. $I_{50}$ is defined as the concentration of inhibitor that produces $50 \%$ inhibition of activity.

Assay for cytosolic phosphatidate phosphohydrolase activity. Activity of this enzyme in liver cytosolic fraction was assayed using membrane-bound phosphatidate as described (1). In agreement with a recent report by Lamb et al. (10), the substitution of $\mathrm{CaCl}_{2}$ for $\mathrm{NaF}$ in incubation mixtures for the preparation of membrane-bound phosphatidate, resulted in an increased labeling of phosphatidate fraction and reduced counts in diglyceride (DG) fraction. Hence this procedure was adopted. Membrane-bound phosphatidate was prepared as follows: Normal rat liver microsomes were

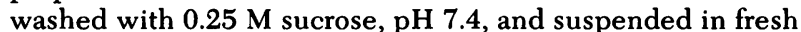
sucrose solution. The incubation mixture contained $100 \mathrm{mM}$ Tris- $\mathrm{HCl}$ buffer, pH 7.4; $70 \mu \mathrm{M}$ CoA; $5 \mathrm{mM}$ ATP; $1.6 \mathrm{mM}$ $\mathrm{Ca}^{2+}$ (as chloride); $6 \mathrm{mM}$ DL-[U- $\left.{ }^{14} \mathrm{C}\right]$ glycero-3-phosphate (15 $\mu \mathrm{Ci}) ; 0.57 \mathrm{mM}$ palmitate bound to purified bovine serum albumin (1) and liver microsomes (about $5 \mathrm{mg}$ protein) in a total volume of $3.5 \mathrm{ml}$. After incubation for $1 \mathrm{~h}$ at $37^{\circ} \mathrm{C}$, the microsomes were sedimented, washed, suspended in fresh sucrose solution, and heated for $2 \mathrm{~min}$ at $100^{\circ} \mathrm{C}$ to destroy microsomal endogenous phosphatidate phosphohydrolase activity (1, 11). The specific activity of the membrane-bound phosphatidate was about $3,960 \mathrm{dpm} / \mathrm{nmol}$.

\section{RESULTS}

A major pathway for hepatic TG synthesis is shown in Fig. 1. In the first series of experiments, triolein sonicates were added to incubation mixtures to study their effect on the synthesis of TG and its precursors. The addition of triolein in micromolar concentrations produced a concentration-dependent inhibition of TG synthesis in liver homogenates of both control and ketotic diabetic rats (Fig. 2). The concentration of triolein that was required to produce half-maximal inhibition was increased in the ketotic diabetic state (Fig. 2). Similar results were obtained in studies on DG synthesis. Triolein had no effect on phosphatidate synthesis by liver homogenates of either control or ketotic diabetic rats. The concentration of triolein required to produce half-maximal inhibition of DG synthesis was higher than that required to produce similar inhibition of TG synthesis (Fig. 2). The addition of sonicates, similarly prepared but without triolein, had no inhibitory effect on either DG or TG synthesis, indicating that the triolein component of the sonicates was responsible for the inhibition. To check the specificity of the inhibitory lipid, these experiments were repeated using monoolein sonicates in place of triolein. Monoolein is structurally related to triolein but is not an intermediate or end product in the hepatic TG biosynthetic pathway (12). Sonicates of monoolein had no inhibitory effect on synthesis of phosphatidate (PA), DG, or TG (Fig. 3).

Since triolein sonicates were unphysiological suspensions, subsequent inhibition studies were done with rat serum VLDL, a physiological form of TG. Serum VLDL, when added in millimolar quantities

TRIGLYCERIDE BIOSYNTHESIS

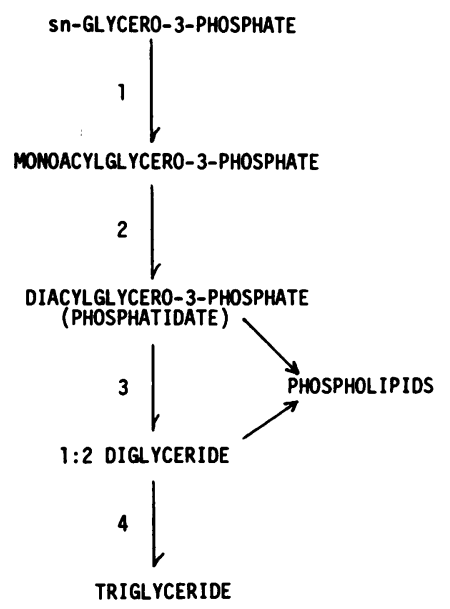

FIGURE 1 The glycerophosphate pathway for triglyceride synthesis. 

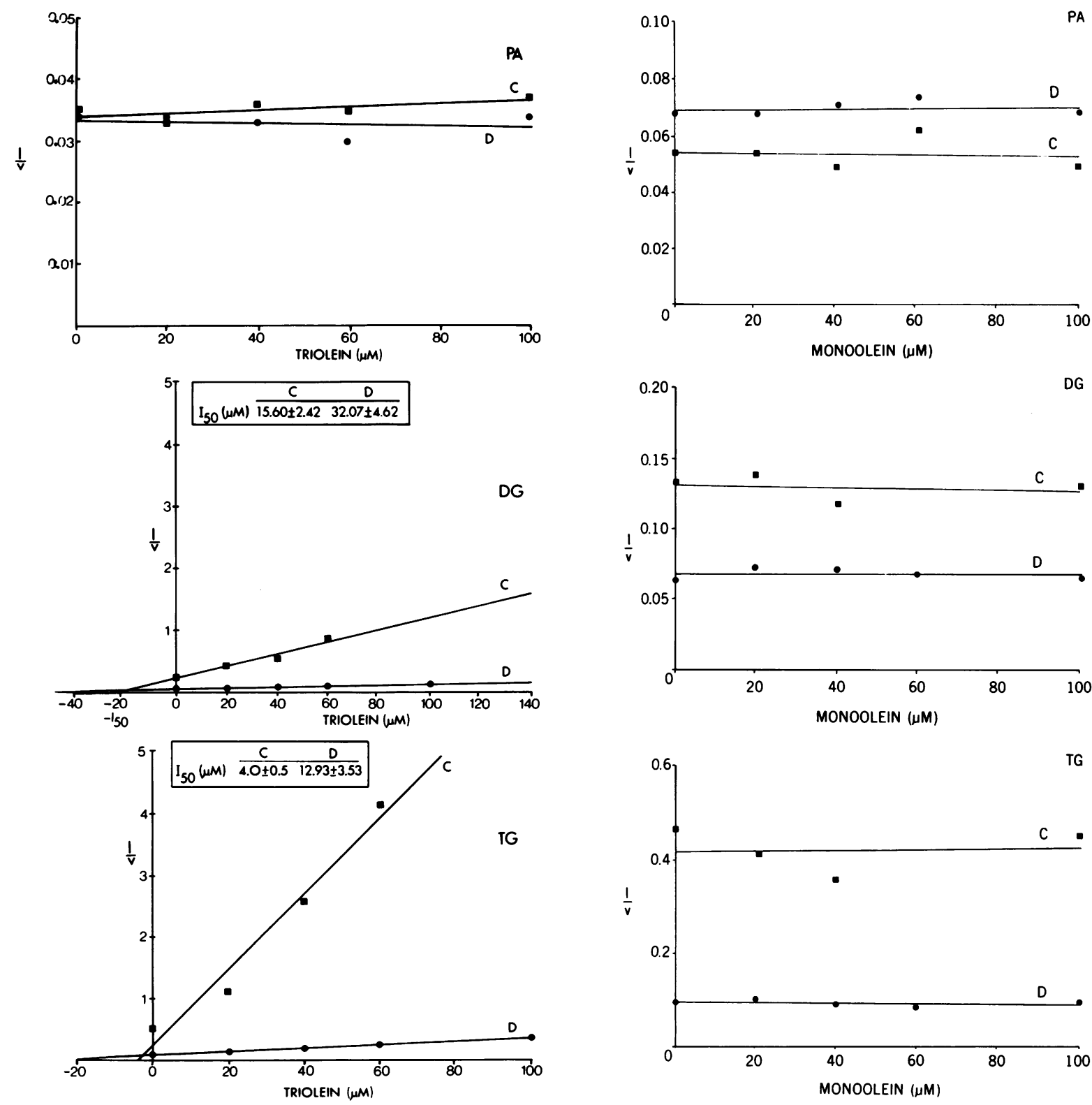

Figure 2 The concentration-dependent inhibition by triolein of DG and TG synthesis in liver homogenates. Inset shows values (mean $\pm S E$ ) for half-maximal inhibition $\left(I_{50}\right)$ in three experiments. In each experiment, livers from four rats in each group were pooled and homogenized. C, control; D, ketotic diabetic rats. Significance: DG-C vs. D, $P<0.05$; TG$C$ vs. $D, P<0.05$. The addition of triolein had no effect on $P A$ synthesis (upper panel).

(VLDL-TG), produced a concentration-dependent inhibition of TG synthesis by liver homogenates of both control and ketotic diabetic rats (Fig. 4). As observed with triolein sonicates, the concentration of VLDL-TG required to produce half-maximal inhibition was increased in liver homogenates of ketotic diabetic rats.

FigurE 3 Effect of monoolein on the synthesis of PA, DG, and TG in liver homogenates.

When the diabetic rats were treated with insulin, which resulted in the reversal to control of various parameters of the diabetic state including plasma glucose, free fatty acids, $\beta$-hydroxybutyrate and TG (1), the halfmaximal value for inhibition of TG synthesis reverted to control (Fig. 4). DG synthesis was also inhibited by added serum VLDL (Fig. 4). The concentration of VLDL-TG required to produce half-maximal inhibition was increased in the ketotic diabetic state, an effect reversed by insulin treatment of diabetic rats. PA synthesis was unaffected by added VLDL (Fig. 4). 

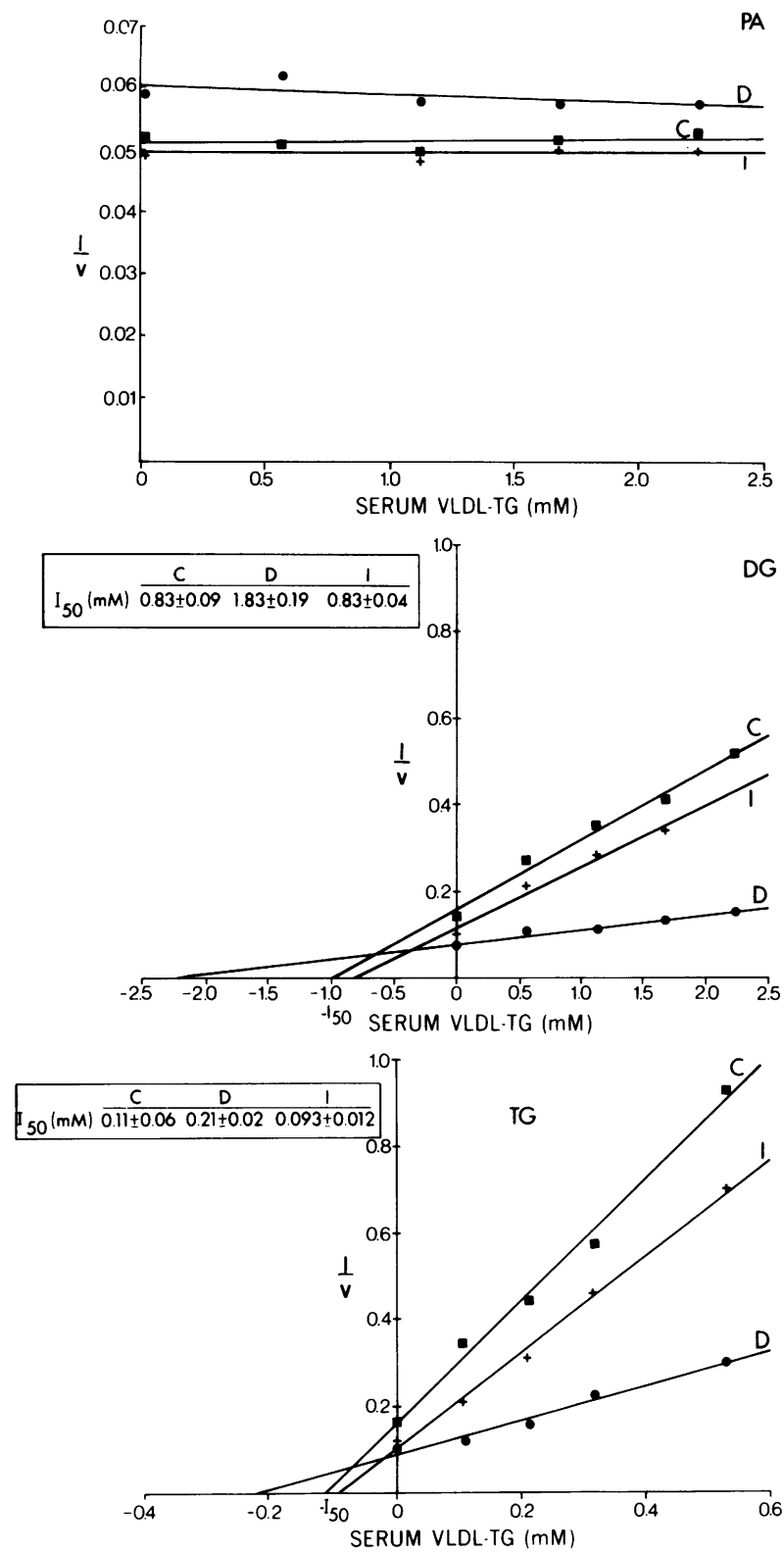

FIgURE 4 The concentration-dependent inhibition by serum VLDL of DG and TG synthesis in liver homogenates of control (C), ketotic diabetic (D), and insulin-treated (I) rats. Inset shows values (mean \pm SE) for half-maximal inhibition $\left(I_{50}\right)$ in three experiments. In each experiment, livers from four rats in each group were pooled and homogenized. Significance: DG-C vs. D, $P<0.01 ; \mathrm{D}$ vs. I, $P<0.01$; $\mathrm{C}$ vs. I, $P>0.05$; TG-C vs. D, $P<0.01 ; \mathrm{D}$ vs. I, $P<0.01$, C vs. I, $P>0.2$. The addition of VLDL had no effect on PA synthesis (upper panel).

The requirement of a higher concentration of serum VLDL by liver homogenates of diabetic rats might have been due to the increased degradation of added VLDL by these homogenates. To test this possibility, doublylabeled serum VLDL was incubated with liver homog- enates of control, ketotic diabetic, and insulin-treated rats. Aliquots of the incubation mixture were removed at 0 min of incubation and at various time intervals. Radioactivity in FFA and TG fractions (2) and the ratio of ${ }^{3} \mathrm{H} /{ }^{14} \mathrm{C}$ were determined. The results demonstrated that the radioactive VLDL was not degraded by liver homogenates of control, diabetic, and insulin-treated rats (Fig. 5A). A constant ratio of ${ }^{3} \mathrm{H} /{ }^{14} \mathrm{C}$ in TG throughout the incubation period (Fig. 5B) and an absence of measurable radioactivity in the FFA fraction (not shown) demonstrated that degradation of serum VLDL followed by its resynthesis did not occur.

Since it can be argued that serum VLDL is not the intracellular form of the lipoprotein, the inhibition studies were repeated using rat liver nascent VLDL. Nascent VLDL, like serum VLDL, produced a concentration-dependent inhibition of TG synthesis by liver homogenates of both control and ketotic diabetic rats (Fig. 6). As observed with serum VLDL, the halfmaximal value for inhibition of TG synthesis by nascent VLDL was increased in the ketotic diabetic state but reverted to control values on insulin treatment of the diabetic rats (Fig. 6). DG synthesis was also inhibited by nascent VLDL. The half-maximal inhibition value was increased in the liver of ketotic diabetic rats but was reversed to control on insulin treatment of the diabetic rats (Fig. 6). PA synthesis was unaffected by the addition of nascent VLDL (Fig. 6). Thus, nascent VLDL reproduced the effects of serum VLDL in the TG biosynthetic pathway.

To study whether the inhibition of TG and DG synthesis could be correlated with the TG content of lipo-
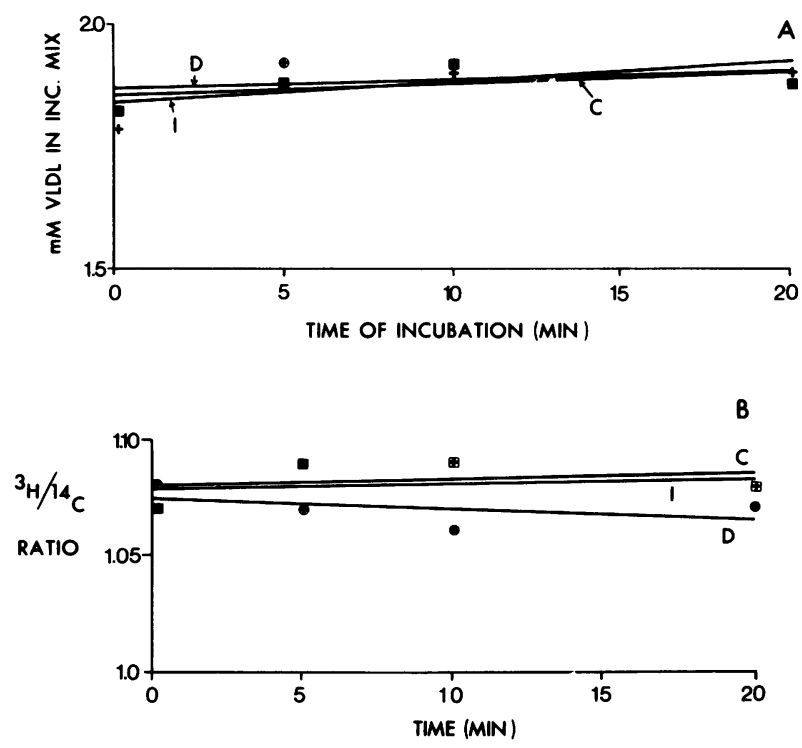

FIGURE 5 Absence of degradation of radioactive VLDL by liver homogenates of control (C), ketotic diabetic (D), and insulin-treated (I) rats. 

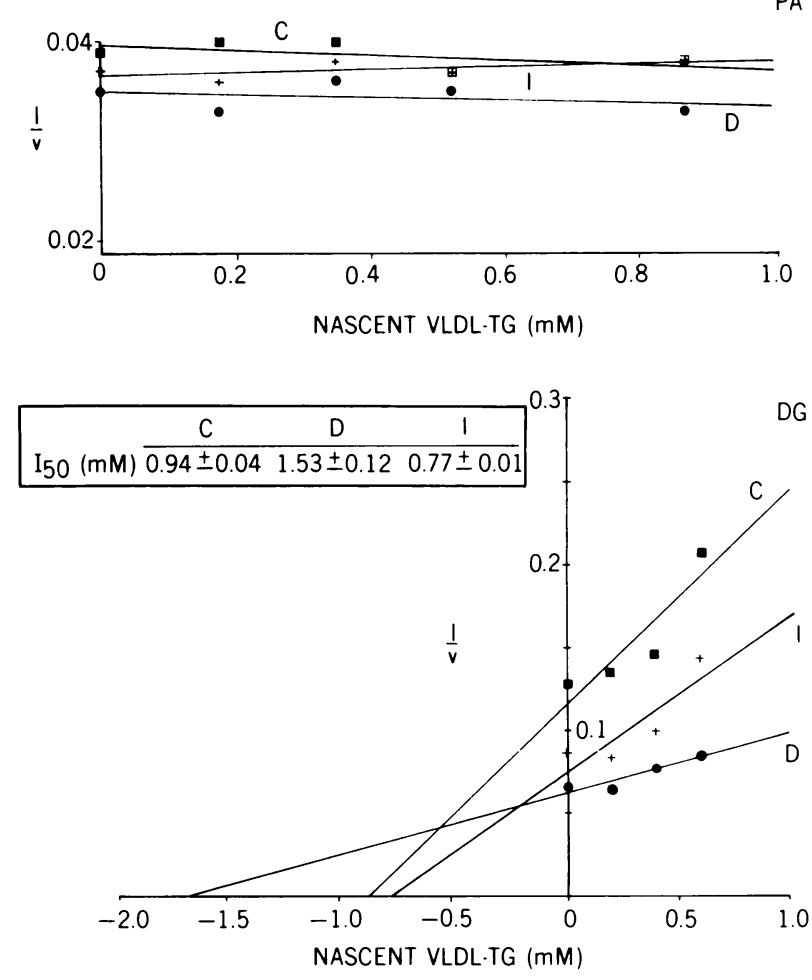

TG

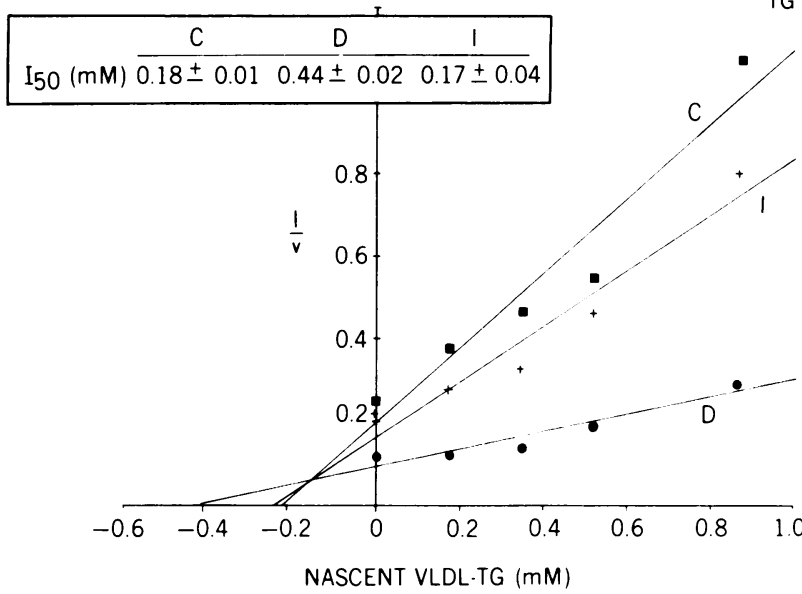

FIgure 6 The concentration-dependent inhibition by nascent VLDL of DG and TG synthesis in liver homogenates. Inset shows values (mean $\pm \mathrm{SE}$ ) for half-maximal inhibition $\left(I_{50}\right)$ in three experiments. In each experiment, livers from four rats in each group were pooled and homogenized. Significance: DG-C vs. D, $P<0.01$; D vs. I, $P<0.01$; $\mathrm{C}$ vs. I, $P<0.02$; TG-C vs. D, $P<0.001$; D vs. I, $P<0.01$; C vs. I, $P>0.2$. The addition of nascent VLDL had no effect on PA synthesis (upper panel).

protein, we repeated the inhibition studies using rat serum HDL. HDL was chosen since it is abundant in rat serum and its TG content is about $6 \%$ (compared with about $55 \%$ in VLDL) (13). Rat serum HDL pro- duced a concentration-dependent inhibition of TG synthesis, with a higher half-maximal inhibition value in the liver homogenates of ketotic diabetic rats (Fig. 7). Insulin treatment of the diabetic rats resulted in the reversal of the half-maximal inhibition value to control (Fig. 7). Similar results were obtained for inhibition of DG synthesis. The results with different lipoproteins and the half-maximal inhibition values suggest that the magnitude of inhibition of TG synthesis by lipoproteins is not a simple function of their TG contents and that the inhibition is more complex. VLDL and HDL differ from each other not only in their TG content but also in such characteristics as size, molecular weight, types of apoproteins, as well as contents of cholesterol, cholesterol esters, phospholipids, and total protein (13). These large differences preclude a comparison of the half-maximal values between VLDL and HDL for inhibition of TG synthesis.

The consistently higher half-maximal inhibition values observed for inhibition of TG and DG synthesis in liver homogenates of ketotic diabetic rats suggested the possibility that the sensitivity of the enzymes of TG synthesis to lipoprotein inhibition was reduced in the ketotic diabetic state. The site of inhibition of TG synthesis by VLDL in the overall pathway (Fig. 1) also remained to be established. In view of the fact that VLDL is the major carrier of TG in vivo and that serum VLDL is prepared with ease and better yield than nascent VLDL, serum VLDL was used as a representative lipoprotein in studies on the localization of the site of inhibition of TG synthesis. VLDL inhibited both DG and TG synthesis in the biosynthetic pathway, effects that suggested inhibition of PA phosphohydrolase activity (enzyme catalyzing step 3 in Fig. 1). Moreover, it has been suggested that PA phosphohydrolase of cytosolic fraction plays an important role in in vitro $(12,14)$ and probably in vivo $(15,16)$ hepatic TG synthesis. The effect of serum VLDL on liver-soluble PA phosphohydrolase activity was assayed directly using membranebound PA as substrate. The results showed that VLDL, in a concentration-dependent manner, inhibited the PA phosphohydrolase activity of the liver-soluble fractions of control, ketotic diabetic, and insulin-treated rats (Fig. 8). The concentration of VLDL required to produce half-maximal inhibition was increased in the ketotic diabetic state but it reverted to control values on insulin treatment of the diabetic rats (Fig. 8).

\section{DISCUSSION}

Our results show that the addition of a physiological form of TG, rat serum VLDL, inhibited DG and TG synthesis without affecting PA synthesis in liver homogenates of control, ketotic diabetic, and insulintreated rats. Thus, VLDL exhibited selective inhibitory effects in the TG biosynthetic sequence. The con- 

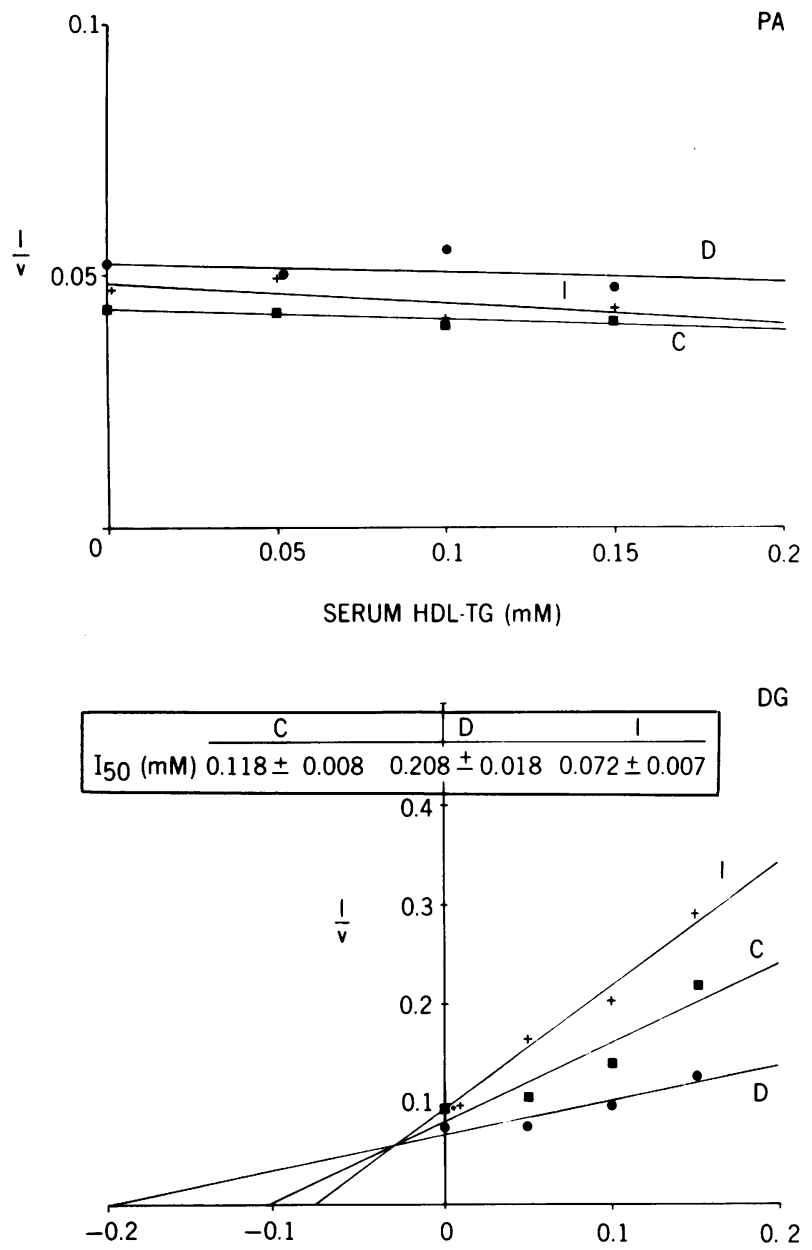

SERUM HDL-TG (mM)

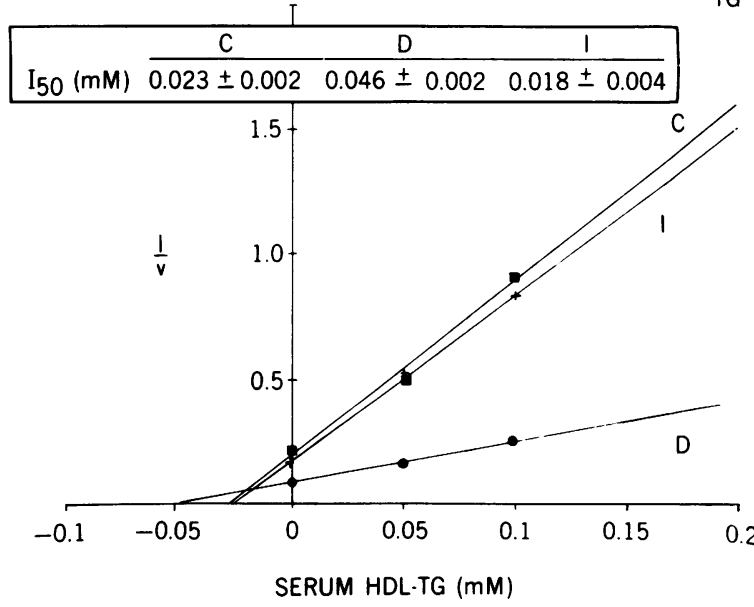

Figure 7 The concentration-dependent inhibition by serum HDL of DG and TG synthesis in liver homogenates. Inset shows values (mean $\pm S E$ ) for half-maximal inhibition $\left(I_{50}\right)$ in three experiments. In each experiment, livers from four rats in each group were pooled and homogenized. Significance:

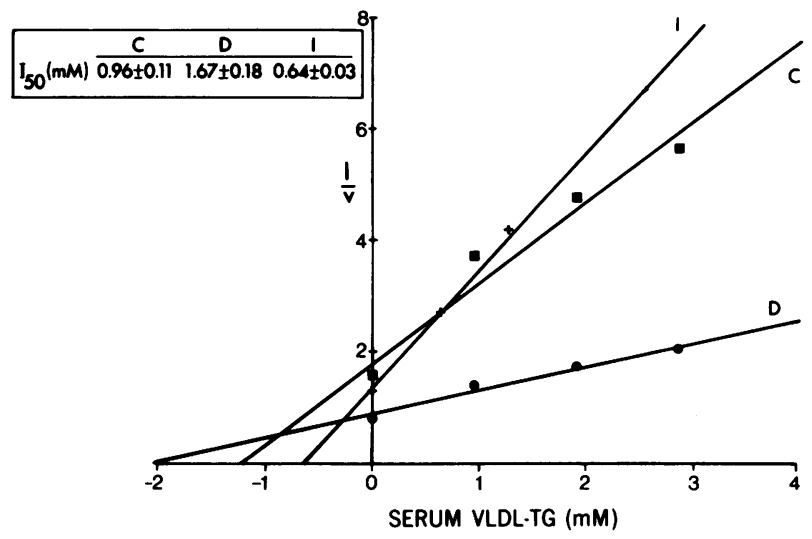

FIGURE 8 The concentration-dependent inhibition by serum VLDL of liver cytosolic PA phosphohydrolase activity. Inset shows half-maximal inhibition $\left(I_{50}\right)$ values (mean $\pm S E$ ) for three experiments. In each experiment, livers from four rats in each group were pooled and soluble fraction prepared. Significance: C vs. D, $P<0.02$; D vs. I, $P<0.01$; C vs. I, $P<0.05$.

centration of serum VLDL required for half-maximal inhibition of DG or TG synthesis was increased in the ketotic diabetic state but, in both cases, reverted to control values on insulin treatment of the diabetic rats. These results showed that the increased requirement of serum VLDL in the diabetic state was a consequence of insulin deficiency. The intracellular form of VLDL, namely nascent VLDL, of rat liver reproduced the inhibitory effects of serum VLDL. Nascent VLDL shares similar morphological, flotational, chemical, and immunochemical properties with serum $\operatorname{VLDL}(5,17)$. Both are complex molecules containing TG, phospholipids, apoproteins, cholesterol, and cholesterol esters as major constituents (13).

Triolein sonicate, when added to incubation mixtures, inhibited the synthesis of DG and TG without affecting PA synthesis and was thus analogous to VLDL in its inhibitory action. It is known that monoolein is an intermediate in the TG biosynthetic sequence in intestinal mucosa $(18)$ but not in liver $(12,19)$. In the present experiments, unlike triolein sonicates, monoolein sonicates had no inhibitory action on DG or TG synthesis thus establishing some specificity of the inhibitory lipid. It is possible that triolein sonicates or VLDL inhibited TG synthesis by a nonspecific binding of substrate, e.g., PA. However, in the present studies the substrates and cofactors have been present in concentrations slightly in excess of saturation. The results of experiments with triolein sonicates suggested that the TG component of VLDL inhibited DG and TG synthesis.

DG-C vs. D, $P<0.02$; D vs. I, $P<0.001$; C vs. I, $P<0.02$; TG$\mathrm{C}$ vs. $\mathrm{D}, P<0.001$; D vs. I, $P<0.01$; $\mathrm{C}$ vs. I, $P>0.2$. The addition of HDL had no effect on PA synthesis (upper panel). 
Further work using rat serum HDL, however, showed that the lipoprotein inhibition of TG synthesis in liver was more complex and was not a simple function of its TG content. The complexity of lipoprotein inhibition of hepatic TG synthesis is further underscored by the fact that the concentration of serum or nascent VLDL required for half-maximal inhibition of TG synthesis was much lower than that required for inhibiting DG synthesis.

In view of the ease of preparation and better yield, further experiments were carried out using serum VLDL. The requirement of a higher concentration of serum VLDL to produce half-maximal inhibition of DG or TG synthesis was not due to the increased degradation of added VLDL by liver homogenates of diabetic rats; in fact, none of the liver homogenates degraded VLDL. Since serum or nascent VLDL inhibited the synthesis of DG and TG without affecting PA synthesis, the results suggested that the locus of inhibition was at the PA phosphohydrolase site. Hepatic PA phosphohydrolase activity has been detected in both microsomal and cytosolic fractions (12). Whether there are two different enzymes or a similar enzyme distributed in two subcellular fractions, or whether the dual location is an artifact due to the trauma of cell breakage, has not been established. Hepatic soluble PA phosphohydrolase activity has been reported to be a rate limiting step in in vitro TG synthesis (14).

We have focused our attention on the hepatic cytosolic PA phosphohydrolase activity because $(a)$ our earlier work demonstrated a marked increase in its activity in the ketotic diabetic state and the reversal of the activity to control values on insulin treatment of the rat ( 1$),(b)$ changes in the activity of this enzyme correlated with changes in the rate of TG synthesis in liver; e.g., high carbohydrate feeding (20), diabetes $(1,21)$, a subtotal hepatectomy (22), alcohol ingestion $(10,23)$, genetic obesity (24), and treatment with lipid-lowering agents $(15,16)$ and $(c)$ Whiting et al. (21) observed that the changes in hepatic TG synthesis in diabetes correlated with changes in PA phosphohydrolase activity of the soluble but not the microsomal enzyme.

Using membrane-bound PA as the substrate, the direct assay of PA phosphohydrolase activity demonstrated that serum V'LDL inhibited the activity of this enzyme. The results also showed that the concentration of VLDL required to produce half-maximal inhibition was increased in the ketotic diabetic state, an effect reversed by insulin treatment of the diabetic rats. Thus VLDL effects on soluble PA phosphohydrolase activity could offer an explanation for its effect on the overall pathway. These results pinpointed an important locus of inhibition of TG synthesis by VLDL in the overall TG biosynthetic sequence and further strengthened the importance of this enzyme in the regulation of hepatic TG synthesis.
Intracellular factors that regulate TG synthesis are not established. Intracellular cyclic AMP concentration (25), monoglyceride concentration (26), and $\mathrm{Ca}^{2+}$ concentration (27) have been proposed to play a role. The results of this study showed that added TG could control TG synthesis in cell-free preparations of liver. Whether such control occurs in the intact hepatocyte is yet to be established. The concentrations of serum VLDL that inhibited the in vitro TG synthesis were in the physiological range found in the serum of normal and diabetic rats $(1,28)$. Furthermore, the intracellular form of VLDL, hepatic nascent VLDL, also inhibited DG and TG synthesis in liver homogenates. The enzymes of TG synthesis are found in the microsomes (and their environment) in the hepatocyte, the same site where nascent VLDL is synthesized (13). These facts suggest that the regulation of TG synthesis by VLDL in the cell is a reasonable possibility. It is interesting to note that Kissebah and colleagues (29) concluded that a defect in feedback regulation of hepatic VLDL synthesis might be a major defect leading to hypertriglyceridemia in diabetic patients. The results of our study showed that there was a reduced sensitivity of PA phosphohydrolase activity to TG in the ketotic diabetic state. These results may explain our previous observation of an increased rate of hepatic TG synthesis in the diabetic state at a time when there was an accumulation of hepatic TG (1).

\section{ACKNOWLEDGMENTS}

We are grateful to Dr. William Dulin, Upjohn Company, Kalamazoo, Mich., for the gift of streptozotocin; Dr. John Galloway, Lilly Laboratory for Clinical Research for the insulin diluent; Mr. William MacArthur for expert technical assistance; Mrs. Patricia Jeanette and Mrs. Jackie Schmidt for secretarial help. We thank Dr. W. W. Cleland for his suggestions on the kinetic analysis of the data in inhibition studies. This study was supported by the Veterans Administration and the Max Baer Eagles Heart Research Fund.

\section{REFERENCES}

1. Murthy, V. K., and J. C. Shipp. 1979. Synthesis and accumulation of triglycerides in liver of diabetic rats: effects of insulin treatment. Diabetes. 28: 472-478.

2. Roncari, D. A. K., and V. K. Murthy. 1975. Effects of thyroid hormones on enzymes involved in fattyacid and glycerolipid synthesis. J. Biol. Chem. 250: 4134-4138.

3. Havel, R. J., H. A. Eder, and J. H. Bragdon. 1955. The distribution and chemical composition of ultracentrifugally separated lipoproteins in human serum. J. Clin. Invest. 34: $1345-1353$.

4. Murthy, V. K., T. C. Monchesky, and G. Steiner. 1975. In vitro labeling of $\beta$-apoprotein with ${ }^{3} \mathrm{H}$ or ${ }^{1+} \mathrm{C}$ and preliminary application to turnover studies. J. Lipid Res. 16: $1-6$.

5. Mahley, R. W., R. L. Hamilton, and V. S. Lequire. 1969. Characterization of lipoprotein particles isolated from the golgi apparatus of rat liver. J. Lipid Res. 10: 433-439.

6. Mahley, R. W., T. P. Bersot, V. S. Lequire, R. I. Levy, 
H. G. Windmueller, and W. V. Brown. 1970. Identity of very low density lipoprotein apoproteins of plasma and liver golgi apparatus. Science (Wash., D. C.). 168: 380-382.

7. Felker, T. E., M. Fainaru, R. L. Hamilton, and R. J. Havel. 1977. Secretion of the arginine-rich and A-1 apolipoproteins by the isolated perfused rat liver. J. Lipid Res. 18: 465-473.

8. Beckman Microzone Agarose Gel Electrophoresis Method Manual. Beckman Instruments, Fullerton, California.

9. Segel, I. H. 1975. Enzyme kinetics: behavior and analysis of rapid equilibrium and steady state enzyme systems. Wiley-Interscience Publication, New York. 227-272.

10. Lamb, R. G., C. K. Wood, and H. J. Fallon. 1979. The effect of acute and chronic ethanol intake on hepatic glycerolipid biosynthesis in the hamster. J. Clin. Invest. 63: $14-20$

11. Jamdar, S. C., and H. J. Fallon. 1973. Glycerolipid synthesis in rat adipose tissue II. Properties and distribution of phosphatidate phosphatase. J. Lipid Res. 14: 517-524.

12. Hubscher, G. 1970. Glyceride metabolism. In Lipid Metabolism. S. J. Wakil, editor. Academic Press, Inc., New York. 279-370.

13. Eisenberg, S., and R. I. Levy. 1975. Lipoprotein metabolism. Adv. Lipid Res. 13: 1-89.

14. Lamb, R. G., and H. J. Fallon. 1974. Glycerolipid formation from sn-glycero-3-phosphate by rat liver cell fractions: the role of phosphatidate phosphohydrolase. Biochim. Biophys. Acta. 348: 166-178.

15. Lamb, R. G., S. D. Wyrick, and C. Piantadosi. 1977. Hypolipidemic activity of in vitro inhibitors of hepatic and intestinal sn-glycero-3-phosphate acyltransferase and phosphatidate phosphohydrolase. Athersclerosis. 27: 147154.

16. Brindley, D. N., M. Bowley, R. G. Sturton, P. H. Pritchard, S. L. Burdit, and J. Cooling. 1977. The control of phosphatidate metabolism by amphiphilic drugs and by bivalent cations. Biochem. Soc. Trans. 5: 40-43.

17. Chapman, M. J., G. L. Mills, and C. E. Taylaur. 1972. Lipoprotein particles from the golgi apparatus of guineapig liver. Biochem. J. 128: 779-787.

18. Johnston, J. M. 1977. Gastrointestinal tissue. In Lipid Metabolism in Mammals. F. Snyder, editor. Plenum Press, New York. 151-188.
19. Van Golde, L. M. G., and S. G. Van Den Bergh. 1977. Liver in Lipid Metabolism in Mammals. F. Snyder, editor, Plenum Press, New York. 35-149.

20. Lamb, R. G., and H. J. Fallon. 1974. An enzymatic explanation for dietary induced alterations in hepatic glycerolipid metabolism. Biochim. Biophys. Acta. 348: 179-188.

21. Whiting, P. H., M. Bowley, R. G. Sturton, P. H. Pritchard, D. N. Brindley, and J. N. Hawthorne. 1977. The effect of chronic diabetes, induced by streptozotocin, on the activities of some enzymes of glycerolipid synthesis. Biochem. J. 168: 147-153.

22. Mangiapane, E. H., K. A. Lloyd-Davis, and D. N. Brindley. 1973. A study of some enzymes of glycerolipid biosynthesis in rat liver after subtotal hepatectomy. Biochem.J. 134: 103-112.

23. Savolainen, M. J. 1977. Stimulation of hepatic phosphatidate phosphohydrolase activity by a single dose of ethanol. Biochem. Biophys. Res. Commun. 75: 511-518.

24. Jamdar, S. C., D. Shapiro, and H. J. Fallon. 1976. Triacyglycerol biosynthesis in the adipose tissue of the obesehyperglycemic mouse. Biochem. J. 158: 327-334.

25. Heimberg, M., E. H. Goh, H. A. Klausner, C. SolerArgilaga, I. Weinstein, and H. G. Wilcox. 1978. Regulation of hepatic metabolism of free fattyacids In Disturbances in Lipid and Lipoprotein Metabolism. J. M. Deitschy, A. M. Gotto, and J. A. Ontko, editors. American Physiological Society, Bethesda, Md. 251-267.

26. Polheim, D., J. S. K. David, F. M. Shultz, M. B. Wylie, and J. M. Johnston. 1973. Regulation of triglyceride biosynthesis in adipose and intestinal tissue. J. Lipid Res. 14: 415-421.

27. Soler-Argilaga, C., R. L. Russell, and M. Heimberg. 1977. Reciprocal relationship between uptake of $\mathrm{Ca}^{++}$and biosynthesis of glycerolipids from sn-glycerol-3-phosphate by rat liver microsomes. Biochem. Biophys. Res. Commun. 78: 1053-1059.

28. Murthy, V. K., and J. C. Shipp. 1977. Accumulation of myocardial triglycerides in ketotic diabetes: evidence for increased biosynthesis. Diabetes. 26: 222-229.

29. Kissebah, A., R. Murray, N. Vydelingum, and C. Hussey. 1980. Extreme hyperlipidemia in mild diabetes: defect in feedback regulation of plasma very low density lipoprotein synthesis. Diabetes. 29: 117A (Abstr.). 